\author{
Abstracta Iranica \\ Abstracta Iranica Revue bibliographique pour le domaine irano-aryen \\ Volume 37-38-39 | 2018 \\ Comptes rendus des publications de 2014-2016
}

\title{
Sheila Blair. Text and Image in Medieval Persian Art
}

\section{Frantz Chaigne}

\section{(2) OpenEdition}

1 Journals

\section{Édition électronique}

URL : http://journals.openedition.org/abstractairanica/42761

DOI : 10.4000/abstractairanica.42761

ISBN : 1961-960X

ISSN : 1961-960X

Éditeur :

CNRS (UMR 7528 Mondes iraniens et indiens), Éditions de l'IFRI

Référence électronique

Frantz Chaigne, "Sheila Blair. Text and Image in Medieval Persian Art », Abstracta Iranica [En ligne], Volume 37-38-39 | 2018, document 20, mis en ligne le 10 mars 2018, consulté le 28 septembre 2020 URL : http://journals.openedition.org/abstractairanica/42761; DOI : https://doi.org/10.4000/ abstractairanica.42761

Ce document a été généré automatiquement le 28 septembre 2020

Tous droits réservés 


\title{
Sheila Blair. Text and Image in Medieval Persian Art
}

\author{
Frantz Chaigne
}

\section{RÉFÉRENCE}

Sheila Blair. Text and Image in Medieval Persian Art, Edimbourg, Edinburgh University Press, 2014, 336 p., 142 ill. couleur, biblio, index (Edinburgh Studies in Islamic Art).

1 Cet ouvrage propose d'explorer les relations entre texte et image en vue d'en décrypter les multiples implications. La démonstration est d'autant plus convaincante qu'après un premier chapitre introductif, l'A se livre à l'analyse d'œuvres relevant de médias et de périodes fort divers : une céramique samanide (Freer Gallery, F.57.24; chapitre 2), un aspersoir d'eau parfumée en métal d'époque ghuride (David Collection, 15/1991; chapitre 3), un monument il-khanide (le mausolée d'Uljaytu à Sultaniyya ; chapitre 4), une miniature jalayiride (BL, Add. 18,113; chapitre 5) et deux tapis safavides (V\&A, 272-1893 et LACMA, 53.50.2; chapitre 6). Chaque chapitre bénéficie d'une abondante iconographie où se répondent l'objet d'étude et des items comparatifs, mais ne relevant pas nécessairement de la même époque, voire du même support. La grande disparité des matériaux et des époques a conduit l'A à opter pour un classement chronologique. Les œuvres sont étudiées selon une méthodologie commune : l'A part d'une description attentive de l'objet, interroge à la fois sa forme, sa fonction et ses inscriptions afin de le resituer dans un contexte de production (ateliers, commanditaires, matériaux, techniques mises en œuvre...), puis une problématique originale inhérente à chaque pièce est alors dégagée. Ainsi, concernant le mausolée d'Uljaytu, l'A se penche sur la postérité du monument, tant chez les souverains mongols que chez leurs rivaux. Une problématique voisine est examinée pour les tapis d'Ardabil, où leur devenir sur site et sa réception en Occident sont successivement abordés. Les illustrations des scènes de mariage du manuscrit timouride de Khwaju Kirmani permettent quant à elles de 
s'interroger sur le rang tenu par la femme au sein de la haute société jalayiride et plus généralement dans le monde islamique, en opérant toujours par mise en perspective.

2 Plus largement, l'ouvrage s'appuie sur des œuvres procurant une véritable délectation pour le regard en vue de saisir dans un mouvement diachronique l'évolution des rôles des commanditaires, ainsi que des designers et des artisans dont on voit les fonctions se scinder. Enfin, la vue élargie que l'A. propose de porter sur les œuvres se révèle particulièrement opérante pour montrer par quelles voies s'opèrent les transmissions de modèles.

\section{AUTEURS}

\section{FRANTZ CHAIGNE}

Chercheur associé, CNRS, Orient \& Méditerranée-«Islam médiéval» 